Çukurova Üniversitesi Mühendislik Mimarlık Fakültesi Dergisi, 35(4), ss. 847-857, Aralık 2020

Çukurova University Journal of the Faculty of Engineering and Architecture, 35(4), pp. 847-857, December 2020

\title{
Çimento Üretim Sektöründe ISO 14001 Çevre Yönetim Sisteminin Enerji Kazanımı ve İklim Değişikliği Üzerine Etkilerinin İncelenmesi
}

\author{
Bülent SARI ${ }^{1}$, Şeyda Y. GEYİK ${ }^{2}$, Olcayto KESKİNKAN"1 \\ ${ }^{1}$ Çukurova Üniversitesi, Mühendislik Fakültesi, Çevre Mühendisliği Bölümü, Adana \\ ${ }^{2}$ Sönmez Çimento Yapı ve Madencilik San. Tic. A.Ş. Yumurtalık Serbest Bölgesi, Ceyhan/Adana
}

Geliş tarihi: $27.10 .2020 \quad$ Kabul tarihi: 30.12 .2020

$\ddot{\mathbf{O z}}$

Bu çalışmada çimento sektöründe faaliyet gösteren bir endüstriyel firmada ISO 14001 Çevre Yönetim Sisteminin enerji kazanımı ve iklim değişikliği üzerine etkileri incelenmiştir. $\mathrm{CO}_{2}$ emisyonunun engellenmesine ek olarak, fosil yakıt kazancı elde edilerek de doğal kaynakların verimli kullanımına katkı sağlanmıştır. Çimento endüstrisi üretim sürecinde ön 1sitıcı ve soğutucudan çıkan isının yeniden kullanımı ve atık malzemelerin geri kazanımı ile enerjiden büyük oranda tasarruf edilebileceği bu çalışmada ortaya konulmuştur. Enerji verimliliğinin iyileştirilmesinin, elektrik ve yakıt tüketiminden kaynaklı $\mathrm{CO}_{2}$ salınımını azalttığı ve ISO 14001 yönetim sistemi kapsamında enerji tüketimleri ve emisyon salımlarının değerlendirilmesi ile $\mathrm{CO}_{2}$ emisyonunun 6811,87 ton oranında azaldığı bulunmuştur. Böylece atmosfere yapılan ton cinsinden $\mathrm{CO}_{2}$ salımının engellendiği ve hedeflerde bu oranın düştüğü hesaplanmıştır. Kurulan yönetim sistemi ile firma bünyesinde proaktif çevre kültürü oluşturulmaya başlanmış ve bunun sonucunda iklim değişikliğine olumlu katkı sunan sonuçlar alınmaya başlanmıştır.

Anahtar Kelimeler: Çevre yönetim sistemi, Çimento, Enerji, Çevre, İklim değişikliği

\section{Investigation of the Impacts of ISO 14001 Environmental Management System on Energy Recovery and Climate Change in Cement Production Sector}

\begin{abstract}
In this study, the effects of ISO 14001 Environmental Management System on energy gain and climate change in an industrial company operating in the cement industry were examined. In addition to preventing $\mathrm{CO}_{2}$ emissions, it has contributed to the efficient use of natural resources by obtaining fossil fuel savings. In this study, it has been demonstrated that a great deal of energy can be saved by reusing the heat from the preheater and cooler in the production process of the cement industry and recovering waste materials. It has been found that improving energy efficiency reduces $\mathrm{CO}_{2}$ emissions from electricity and fuel consumption and $\mathrm{CO}_{2}$ emission decreased by 6811.87 tons by evaluating energy consumption and release of emissions within the scope of ISO 14001 management system. Thus, it has been calculated that the $\mathrm{CO}_{2}$ emission to the atmosphere in tons was prevented and this rate decreased in the targets. With the established management system, a proactive environmental culture has been created within the company, and as a result, positive contributions to climate change have been obtained.
\end{abstract}

Keywords: Environmental management system, Cement, Energy, Environment, Climate change

*Sorumlu yazar (Corresponding author): Olcayto KESKINKAN, olcayto@cu.edu.tr 
Çimento Üretim Sektöründe ISO 14001 Çevre Yönetim Sisteminin Enerji Kazanımı ve İklim Değişikliği Üzerine Etkilerinin Incelenmesi

\section{GíRiș}

Çimento, günümüzde en temel yapı malzemesi olan betonun su ile birlikte temel bağlayıcısıdır [1]. Üretimine başlandığı 1845 yılından bu yana, çimento, en önemli yapı malzemesi olma niteliğini kaybetmemiştir. Türkiye ekonomisinin son yıllarda kaydettiği hızlı büyümede inşaat sektörü ve sektörün en önemli bileşenlerinden birisi olan çimento sanayi önemli bir katkıya sahiptir [2]. Ülkemizde 54 adet entegre çimento fabrikası bulunmaktadır. Bu fabrikaların hepsi özel sektöre ait olup, iki tanesi yaş diğerleri ise kuru sistemle üretim yapmaktadır [1]. Faaliyet gösteren çimento fabrikaları Avrupa Standartları (EN) ile uyumlaştırılmış olan ve Ülkemizde TS EN olarak adlandırılan standartlar çerçevesinde üretim gerçekleştirmektedir. Türkiye'de çimento üretimi 2015 yılında 72,8 milyon ton iken 2016 yılında yaklaşık 76,9 milyon ton olarak gerçekleşmiş ve $\% 5,6$ oranında bir artış görülmüştür [3]. Çimento sektörü enerji tüketimi en yüksek sektörler arasında yer almaktadır. Enerji tüketiminin yüksek olduğu bu tip sanayi kollarında, enerji tasarrufu ile hedeflenen; enerji girdilerinde sürekliliği yakalayarak düşük maliyetin ve ürün kalitesinin elde edilmesidir [4]. $\mathrm{Bu}$ nedenle çimento sanayinde enerjinin etkin kullanımı, enerji verimliliği, enerji tasarrufu, çevresel etkilerin azaltılması gibi konularda Ar-Ge çalışmaları ve temiz üretim yöntemleri uygulama çabaları yoğunlaşmıştır $[5,6]$.

Sanayi kuruluşları üretim faaliyetleri için ihtiyaç duyulan enerji tüketimini ve üretim sırasında ortaya çıkan çevresel etkileri azaltmak ve ayrıca zorlu rekabet koşulları ile mücadele edebilmek amacıyla çeşitli yönetim sistemlerini kuruluşlarında hayata geçirmektedir [7]. Bu kapsamda Çevre Yönetim Sistemi (ÇYS), sanayi kuruluşlarının en çok başvurdukları yönetim sistemlerinden birisidir [8].

$\mathrm{Bu}$ çalışmada çimento sektörüne ISO 14001 ÇYS'nin uygulamalarının incelenmesi amaçlanmıştır. Belirlenen amaç doğrultusunda ulaşılması beklenen hedefler ise çimento sektöründeki ISO 14001-ÇYS uygulaması ile sağlanacak enerji kazanımı ve bunun iklim değişikliğine olan katkısının ortaya konmasıdır. Bu amaç ve hedefler kapsamında ISO 14001 ÇYS uygulama alanı olarak Adana da bulunan bir entegre çimento üretim tesisi seçilmiştir. Çimento sektöründe ISO 14001 ÇYS uygulanması ve bunun iklim değişikliği özelinde sağlayacağı katkıların ortaya konulmasının, hem yönetim sisteminin uygulanmasının teşvik edilmesi hem de günümüzün en önemli problemlerinden birisi olan iklim değişikliğine dikkat çekmek açısından önemli olduğu düşünülmektedir.

\section{2. ÖNCEKİ ÇALIŞMALAR}

$\mathrm{Bu}$ araştırmanın konusuyla ilgili olarak yapılmış önceki çalışmalar incelendiğinde, Doğanay [9] tarafindan yapılan çalışmada ÇYS incelenerek, tekstil endüstrisinde ÇYS uygulanması esasları üzerinde durulmuştur. Araştırma sonucunda Türkiye'de büyük kuruluşlar hariç, gönüllü olarak bu sistemin kuruluşunu gerçekleştiren kuruluş sayısının oldukça az olduğu tespit edilmiştir. Türkiye'de kuruluşlar kaynak yönetimine geçemediği için bunların doğurduğu organizasyonel problemler herhangi bir sistemin hayata geçirilmesini engellemektedir. Ayrıca veri eksiklikleri büyük problemler yaratmaktadır. Ofori ve arkadaşları [10] şirketlerin ISO 14000-Çevre Yönetim Standartları'na yaklaşımlarını anlamak gayesi ile Singapur'da bir anket araştırması yapmıştır. Yapılan anket araştırmasında inşaat sektöründeki firmaların uygulama maliyetinin yüksek olduğu belirtilmiştir. Böylece elde edilecek faydaların uygulama maliyetinden daha az öneme sahip olması düşüncesi oluşmuştur. Khurana ve arkadaşları [11], çalışmalarında Hindistan'da bulunan ve yıllık klinker kapasitesi 1 milyon ton olan bir çimento üretim fabrikasını incelemiştir. Çimento üretiminde harcanan $1 \mathrm{~s} 1$ enerjisinin yapılan hesaplamalara göre \%35'inin sıcak gaz hatlarında yitirildiği ve yaklaşık olarak da 4,4 MW atık 1sıdan elektrik enerjisi elde edilebileceği görülmüştür. Yapılan hesaplamalar fabrikanın harcadığ 1 enerjinin yaklaşık \%30'luk bir bölümüne denk gelmiştir. Çalışma sonunda enerji verimliliğinin \%10 oranında iyileştiği sonucuna ulaşılmıştır. 
Melnyk ve arkadaşları [12], çalışmalarında ÇYS'nin yürütülmesinde firmaların 3 farklı yol izlediğini tespit etmişlerdir: ÇYS'nin gayri resmi yürütülmesi (1), ÇYS'nin resmi olarak yürütülmesi fakat standart ile belgelendirilmemesi (2) ve ÇYS' nin resmi olarak yürütülüp ISO 14001 standardı ile belgelendirilmesi (3). Gayri resmi ÇYS uygulamasında performansın çok düşük olduğu ifade edilmiştir. ÇYS'nin resmi olarak uygulandığ ancak standartlar ile belgelendirilmediği durumlarda performans ve çevresel seçimlerin orta düzeyde olduğunu bildirilmiştir. Resmi olarak yürütülen ve standartlarla belgelendirilmiş ÇYS'nin uygulanması durumunda ise özellikle atık azaltılması konusunda pozitif performans gösterdiği bildirilmiştir. Fryxell ve arkadaşları [13], yaptıkları çalışmada ÇYS belgelendirilmesi için Çin'deki firmaların üzerine inceleme yapmışlardır. Çalışmada sonuç olarak ÇYS için en güçlü yönleri; mevzuata uygunluğun güvence altına alınması, firma imajının güçlü tutulması ve çevresel performansın iyileştirilmesi olarak tespit edilmiştir. Bektaş [14], TS EN ISO14001 çevre yönetimi standardının kuruluşlarda nasıl şekillendiğini ve madencilik sektöründe uygulamaya nasıl geçebileceğini araştırmıştır. Araştırmanın sonucunda; bu sistemi kuran ve belli bir süre işleten kuruluşların, belgelendirme talebi için başvurabileceği, bu belge ile sektörlerinde çevrenin korunması ve çevre bilinçli üretim konularında önder olabileceği, "Kalite ve Çevre Yönetim Sistemleri için Kılavuz" standardı ile ikisini bir arada belgelendirilebileceği belirlenmiştir. Erdoğan [2]'ın çalışmasında, Türk ve Dünya çimento sanayisinin üretim, tüketim ve dış ticaret gibi temel verileri ile sektörün üretim teknolojisi, enerji tüketimi, sektör kaynaklı emisyonlar ve Türkiye'nin emisyonların azaltılması konusunda mevcut ve muhtemel yükümlülükleri incelenmiştir. $\mathrm{AB}$ emisyon ticaret planının (ETS) getireceği maliyet artışlarının sektörün rekabet gücünü nasıl etkileyeceği analiz edilmiştir. $\mathrm{Bu}$ yükümlülükler kapsamında enerji verimliliğinin artırılarak emisyonların azaltılmasına yönelik olarak sektörde yapılabilecek çeşitli uygulamalar tespit edilmiştir. Tespit edilen uygulamaların Türk çimento sanayisine uygulanma imkanlarına yer verilmiştir. Worrell ve arkadaşları [15]'nın yaptığı çalışmada, endüstriyel enerji verimliliği teknolojilerinin, enerji kullanımının ve sera gazı emisyonlarının 2030 yılına kadar azaltma politikalarının potansiyel katkısı tartışılmaktadır. Sonuç olarak; Endüstri doğrudan ve dolaylı olarak küresel sera gazı emisyonlarının yaklaşık \%37'sine katkıda bulunmaktadır. Enerji kaynaklı toplam endüstriyel emisyonlar 1971'den bu yana \%65 oranında arttığı belirtilmiştir. Bilgideki temel boşluklar, özellikle geçiş ekonomilerinde, enerji yoğun olmayan sanayilerde potansiyel enerji verimliliği iyileştirme potansiyeli, ortak faydaların belirlenmesi, sürdürülebilir kalkınma azaltma seçenekleri ve tüketici tercihlerinin etkisi olduğu tespit edilmiştir. Wang ve arkadaşları [16]'nın yaptığı çalışmada çimento üretimi faaliyetlerinin çok fazla enerji tükettiği üzerinde durulmuştur. Araştırmanın sonucunda ön isitıcıdan döner firın bacasına giden atık 1sının geri kazanılması ile enerji kazanımı öngörülmüştür. Sistem matematiksel olarak modellenmiştir. Hasanbiegi ve arkadaşları [17], yaptıkları çalışmada 16 adet çimento fabrikasını incelemişlerdir. Çimento için kıyaslama ve enerji tasarruf aracı (best-cement) yöntemi ile uluslararası uygulamaları incelemişlerdir. Ayrıca fabrikaların tükettiği enerji göz önüne alınarak Çin'deki yerli uygulamalar ile de karşılaştırmalar yapılmışlardı. Bu çalışmalar sonucunda ortalama olarak \%12'lik bir enerjinin tasarruf edileceği kanaatine ulaşmışlardır. Aydın ve Bedük [18], Karaman'daki imalat işletmelerinin çevre yönetimiyle ilgili mevcut durumlarını tespit etmek amaciyla anket yapmışlar ve sonuçları değerlendirmişlerdir. Çalışmada çevresel hassasiyetler küçük ve orta ölçekli işletmelerin ÇYS standartlarına ne kadar uzak olduklarını anlamak üzere değerlendirilmiştir. Yapılan anket değerlendirmesi sonucunda bu işletmelerde çevre yatırımlarını yönlendirebilecek uzman personelin bulunmadığı, bu yatırımları bir rekabet firsatına çevirme bilinci oluşmadığ 1 ve çevre yatırımlarının yetersiz olduğu sonucuna ulaşılmıştır. Madlool ve arkadaşları [19], Çimento endüstrisinin farklı bölümlerinde enerji kullanımı, spesifik enerji tüketimi, enerji kullanım tipleri, çimento üretim işlemlerinin detayları, çeşitli enerji tasarruf önlemlerini gözden geçirmişlerdir. Uygulama maliyetiyle birlikte tasarruf edilebilecek enerji miktarı dikkate alınarak çeşitli enerji tasarruf önlemlerini eleştirel bir şekilde analiz etmişlerdir. 
Enerji analizinin üretim hattında uygulanmasının, sistemin performansını iyileştirmek ve enerji maliyetlerini düşürmek için etkili bir yol olduğu sonucuna ulaşmışlardır. Ertuğrul ve Şavlı [20], yaptıkları çalışmada bakır sanayinde faaliyet gösteren bir sektöre, standartların kullanım kılavuzundan yararlanılarak ÇYS'nin nasıl uygulanacağını açıklamışlardır. ÇYS'nin verimli bir şekilde yürütülebilmesi için çalışan herkesin tam katılım sağlamasının önemini vurgulamışlardır. Sonuç olarak, çevre yönetim sistemleri işletmeler için maliyetli olsa da işletmenin müşteriler için önemini ve firma imajını güçlendirmek gibi daha birçok yarar sağladığını belirtmişlerdir. Hasanbeigi ve arkadaşları [21], yaptıkları çalışmada 19 çimento ve beton üretim tesisi için ortaya çıkan enerji verimliliği ve $\mathrm{CO}_{2}$ emisyonu azaltma teknolojilerini açıklamışlardır. Gelişmekte olan veya gelişmiş enerji verimliliği ve düşük karbonlu teknolojiler konusunda çimento sektörüne ait bilgilerin sınırlı olduğunu ifade etmişlerdir. Bunun yanında, enerji cezalarını en aza indirmek için bu teknolojileri geliştirmek ve optimize etmek için daha fazla araştırmaya ihtiyaç olduğunu ifade etmişlerdir. Mikulčić ve arkadaşları [22], küresel sera gazı yayılımlarında çimento sektörünün önemli payı olduğunu, daha temiz ve daha enerji verimli çimento üretiminin giderek artan bir ilgi gördüğünü, diğer sanayilerin yan ürünleri gibi alternatif yakıtların ve hammaddelerin kullanım oranının arttığını ifade etmiştir. Çimento endüstrisinde 2020 y1lı ve sonrası için öncelikli hedef $\mathrm{CO}_{2}$ emisyonunun azaltılması olarak belirlenmiştir. Özellikle kireçtaşı ayrışmasından ve fosil yakıt yanmasından kaynaklanan $\mathrm{CO}_{2}$ emisyonlarını azaltacak Ar-Ge faaliyetleri üzerinde yoğunlaşılmıştır. Sonuç olarak, farklı atık ve malzemelerin çimento sektöründe alternatif yakıt/enerji kaynağı olarak kullanılmasının uygunluğu bu çalışmada desteklemiş ve pekiştirilmiştir. Van Ruijven ve arkadaşları [23], çimento üretiminde daha verimli teknolojilerin kullanımı yönünde istek olduğunu ifade etmiştir. Karbon yakalama ve ayrıştırma işlemlerinin büyük salım azaltmalarına ulaşmak için önemli bir teknoloji olduğunu vurgulamıştır. Bilgiç [3], çalışmasında iklim değişikliği ile mücadelede emisyon ticareti ve Türkiye uygulamasını araştırmıştır. İklim değişikliği ve emisyon ticaretinin yer aldığ 1 mevzuatlar incelendiğinde kapsayıcı bir yasal mevzuatın bulunmadığ 1 görülmüştür. Gelecekte ülkemizde bu çalışmaların tasarlanması halinde yasal, kurumsal ve finansal alt yapı boşluklarının analiz edilmesi gerektiğini değerlendirmiştir. Topçu [24], iklim değişikliği ve enerji politikaları bağlamında düşük karbon ekonomisine geçiş hedefi için fosil yakıt sektörünün belirleyiciliğinin devam etmekte olduğunu, düşük karbon teknolojilerinin sağlayıcısı olarak gelişmiş ülke ve endüstrilerin tekel konumlarını sürdürmekte olduğunu ve emisyon ticareti gibi piyasa temelli mekanizmaların şirketler açısından yeni kazanç alanları olarak desteklenmekte olduğunu örneklerle sunmuştur. Orhan [25]'ın yaptığı çalışmada entegre bir pilot tesis seçilmiştir. Pilot tesisten alınan veriler doğrultusunda IPCC (Uluslararası İklim Değişikliği Paneli) kılavuzunda yer alan Tier 1, Tier 2 ve Tier 3 yöntemleriyle baz alınan 2015, 2016 ve 2017 yılları için sera gazı emisyonları hesaplanmıştır. Yapılan çalışmada sonuç olarak, en güvenilir yöntemin Tier 3 olduğu bulunmuştur. Yoğun enerji kullanan sektörlerden olan çimento sektöründe sera gazı emisyonlarının azaltılması ve doğal kaynak tüketiminin sınırlı tutulabilmesi açısından alternatif yakıt kullanımının büyük önem taşıdığı tespit edilmiştir. Ülkemizin nüfusu artışı yüksek bir ülke olduğundan mevcut durumdaki atıkların gelecekte daha da fazla olacağı ve katı atık bertarafları için daha fazla alan kullanımı söz konusu olacağı ve atık kullanımı ile katı atık depolama alanları açısından da kazanç sağlanacağı tespit edilmiştir.

\section{MATERYAL VE METOT}

\subsection{Materyal}

\subsection{1. İşletme Bilgileri}

Uygulama, ISO 14001 ÇYS'nin enerji kazanımı ve iklim değişikliği üzerine etkilerini gerçekleştirmek isteyen Sönmez Çimento Fabrikası'nda yapılmıştır. 413 dönümlük sahası ve 230 çalışanıyla hammadde kaynaklarına çok yakın olan Sönmez Çimento, serbest bölgeler içerisine kurulmasına izin verilen Türkiye'deki ilk çimento fabrikasıdır. 


\subsection{Metot}

Tesiste klinker üretimi ve yakıtların yanmasından kaynaklanan $\mathrm{CO}_{2}$ emisyonlarının hesaplanmasında Hesaplama Temelli Yöntemi'nden (HTY) yararlanılmıştır. HTY uygulanırken yakıtların yanması ve prosesten kaynaklanan sera gazı emisyonları göz önünde bulundurulur. Bu şekilde Faaliyet Verisi belirlenir. Yakıtların yanması sırasında tüketilen yakıta ait veriler kullanılırken; prosesten kaynaklanan emisyonlarda giren ve çıkan malzemeye ait veriler ya da kütle denge yöntemi kullanılır. HTY, ölçüm sistemleri vasıtasıyla kaynak akışlarından elde edilen faaliyet verilerinin, laboratuvar analizlerinden elde edilen veya varsayılan ilave parametrelerin kullanılarak emisyonların belirlenmesi anlamına gelir [Bkz. İ\&R Tebliği Madde 19 (1)]. Klinker stok değişiminin yanı sıra klinker sevkini ve klinker teminini dikkate alan malzeme dengesi vasitası ile çimento teslimatlarına bağlı olarak Eşitlik 1 kullanılır:

$\ddot{\mathrm{UK}}=\left[(\mathrm{TEÇ}-\mathrm{ÇSD}) * \frac{\mathrm{K}}{\mathrm{C}}\right]-(\mathrm{TEK})+(\mathrm{DK})-(\mathrm{KSD})$

Eşitlikte; ÜK, Üretilen klinker, TEÇ, Teslim edilen çimento, ÇSD, Çimento stok değişimi, K, Klinker, Ç, Çimento, TEK, Temin edilen klinker, DK, Dağıtılan klinker, KSD, Klinker stok değişimi olarak tanımlanmıştır.

\subsubsection{ISO 14001 ÇYS'nin Kurulması}

Firma, 10 maddeden oluşan TS EN ISO 14001 ÇYS standardına uygun olarak dokümantasyon çalışmaları yapmıştır. Öncelikli olarak taahhüt edilen çevre politikası oluşturulmuştur. Ardından birimler enerji kazanımlarını ve iklim değişikliğine olan etkilerini çevre boyutları formuna işlemiştir. Böylece $\mathrm{CO}_{2}$ emisyonunun ve elektrik tüketiminin azaltılması için Atık Isıdan Elektrik Enerjisi Üretimi (WHR) tesisinin projelendirilmesi üzerinde çalışmalar yapılmıştır.

WHR Tesisinin maksimum kapasitesi, çimento fabrikasının maksimum klinker üretim miktarı üzerinden hesaplanmıştır. Fabrikaların enerji verimliliği şartlarına bağlı olarak, WHR ile elektrik üretimi 30-45 kw/ton-klinker aralığında değişmektedir. Atık 1sıdan enerji kazanımı hesaplama sonuçları bulgular kısmında verilmiştir.

\subsubsection{Enerji Verimliliği ve İklim Değişikliğine Etkisi}

ISO 14001 ÇYS kurulumunda enerji kazanımı için WHR tesisinin kurulumu planlanmıştır. $\mathrm{Bu}$ doğrultuda kurulacak tesis için araştırmalar yapılmıştır. Sera Gazı Emisyonlarının Takibi Hakkında Yönetmelik kapsamında sera gazlarının izlenmesine dair çalışmalar başlatılmıştır. $\mathrm{Bu}$ bağlamda ton başına düşen $\mathrm{CO}_{2}$ emisyon miktarları hesaplanmıştır. Hesaplamada kullanılan eşitlikler Çizelge 1 ve 2'de verilmiş ve tanımlanmıştır.

Çizelge 1. Yakıtların yanması için emisyon hesaplama formülü

\begin{tabular}{|l|c|}
\hline \multicolumn{2}{|c|}{ Emisyon $=\mathbf{F V} * \mathbf{E F} * \mathbf{N K D} * \mathbf{Y F}$} \\
\hline Parametre & Birim \\
\hline Emisyon & $\mathrm{tCO}_{2}$ \\
\hline FV: Faaliyet Verisi & $\mathrm{TJ}, \mathrm{t}$ ya da Nm \\
\hline NKD: Net Kalorifik Değer & $\mathrm{TJ} / \mathrm{Gg}$ \\
\hline EF: Emisyon Faktörü & $\mathrm{tCO}_{2} / \mathrm{TJ}, \mathrm{tCO}_{2} / \mathrm{Nm}^{3}$ \\
\hline YF: Yükseltgenme Faktörü & birimsiz \\
\hline
\end{tabular}

Çizelge 2. Proses emisyonları için hesaplama formülü

\begin{tabular}{|l|l|}
\hline \multicolumn{2}{|c|}{ Emisyon $=\mathbf{F V} * \mathbf{E F} * \mathbf{D F}$} \\
\hline Parametre & Birim \\
\hline DF: Dönüşüm Faktörü & Birimsiz \\
\hline
\end{tabular}

\section{BULGULAR ve TARTIŞMA}

\section{1. Çimento Sektöründe ISO 14001 Standart Maddeleri Bazında Uygulama Değerlendirilmesi}

Model alınan çimento fabrikasında çevre uygulamaları ISO-14001 ÇYS standartlarına uygun biçimde yürütülmüştür. Standart enerji kazanım hedeflerine ve iklim değişikliğine entegre olarak hazırlanan programın yürütülmesi ve 
Çimento Üretim Sektöründe ISO 14001 Çevre Yönetim Sisteminin Enerji Kazanımı ve İklim Değişikliği Üzerine Etkilerinin Incelenmesi

güvenilirliği akredite belgelendirme kuruluşu denetimi ile desteklenmiștir.

\subsubsection{Kuruluşun Bağlamı}

Terrados ve arkadaşları [27], bu aşamada ilk olarak Şekil 1'de yer alan ilgili taraflar oluşturulmuştur. Tehditleri (riskleri) ve firsatları belirlemek için de SWOT analizi yapılmıştır. SWOT analizinde kurum içi güçlü ve zayıf yanlar ile kurum dışı firsatlar ve tehditler (riskler) tespit edilmiştir. Çizelge 3'de örnek alınan tesis için hazırlanan SWOT Analizi verilmiştir. Fryxell ve arkadaşları [13], ÇYS açısından Çin'deki firmaların en güçlü yönlerini yasalara uyumluluğu sağlamak, firma imajını güçlendirmek ve çevresel performansı artırmak olarak tespit etmiştir.

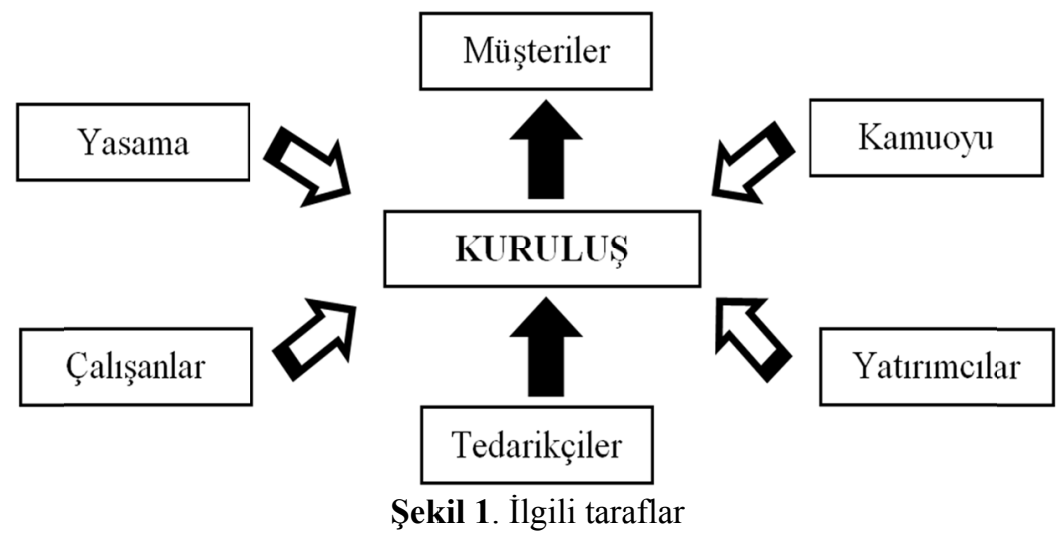

\subsection{Atık Yönetimi}

Tesisin üretim sürecindeki faaliyet, ürün ve hizmetlerinden kaynaklanan, çevreye doğrudan veya dolaylı etkileri olan atıkların etkin bir şekilde yönetilmesi ve bertaraf edilmesi amacı ile "Atık Yönetimi Prosedürü” oluşturulmuştur. Atıklar, rutin prosesler, uygunsuzluklar, acil durumlar veya taşeron faaliyetleri sonucu oluşmaktadır. Taşeronların atık yönetimi ile ilgili yükümlülükleri taşeronlarla yapılan sözleşmelerde belirtilmiştir. ÇYS kurulmadan önce ayrı ayrı toplanmayan atıklar, ÇYS sürecinde atıkların kaynağında azaltılması, geri kazanılması veya tekrar kullanılabilmesi için cinslerine göre ayrı toplanmaya ve depolanmaya başlanmıştır.

Tehlikeli Atıklar için geçici atık depolama alanı yapılmıştır ve atık alanındaki tüm bölmeler kilitlenmiştir. Hurda atıklar, tahta palet atıkları ve diğer tehlikesiz atıklar için ayrı alanlar yapılmıştır. Böylece atık ayrıştırmada \%95 verim sağlanmıştır.

\subsubsection{Alternatif Hammadde Kullanımı}

Klinker üretimi, ihtiyaç duyulan 1 sıl enerji ve kalsinasyon etkisi ile açığa çıkan $\mathrm{CO}_{2}$ emisyonu sebebiyle çimento üretiminin iklim değişikliğine olan etkisinin en belirgin şekilde ortaya çıktığ prosestir. Bu nedenle çimento içindeki klinker oranı ne kadar yüksek olursa üretilen çimentonun iklim değişikliği faktörü de o denli yüksek olacaktır. Modern çimento üretim teknolojisi uygulamalariyla, klinkerin alternatif hammaddelerle ikame edilmesi olanak dahilindedir. $\mathrm{Bu}$ modern uygulamalarla üretilen yüksek performanslı, katkılı çimento türleri, üretim için harcanan toplam enerji miktarını ve $\mathrm{CO}_{2}$ emisyonunu düşürmektedir. Mikulčić ve arkadaşları [22], çimento sektöründe iklim değişikliğinin modern toplumun karşılaştığı en büyük zorluklardan biri olduğunu ifade etmiştir. $\mathrm{Bu}$ kapsamda sektörün 2020 y1lı hedeflerine ulaşması için $\mathrm{CO}_{2}$ emisyonunun azaltılması önem kazanmıştır. Bunun için farklı atık yakıt ve 
malzemelerin alternatif enerji kaynağı ve hammadde olarak kullanılmasının uygunluğu desteklenmiştir.

Yürütülen çalışmada kaynakların daha verimli kullanılabilmesi için alternatif hammadde kullanımının artırılması ÇYS hedeflerine eklenmiştir. 2020 yılının ilk yarısında katkı maddesi olarak uçucu kül kullanımı \%50 oranında artırılmıştır.

Çizelge 3. SWOT analizi

\begin{tabular}{|c|c|}
\hline GÜÇLÜ YÖNLER & FIRSATLAR \\
\hline $\begin{array}{l}\text { - Filtre seçiminin torbalı filtre oluşu sayesinde } \\
\text { daha sağlıklı ortam oluşturma } \\
\text { - Geçici Depolama Alanının yanında bulunan } \\
\text { kör kuyu sayesinde dış ortamın kirliliğinin } \\
\text { önlenmesi } \\
\text { - Üst yönetimden yeterli desteğin alınabilmesi } \\
\text { - Sürekli emisyon ölçüm sisteminin online } \\
\text { olarak izlenebilmesi ve rutin bakımlarının } \\
\text { zamanında yapılabilmesi } \\
\text { - Güncel çevre eğitimlerinin fabrika tarafından } \\
\text { sunulması }\end{array}$ & $\begin{array}{l}\text { - Hava emisyonu ve atık kabul tesisi konulu } \\
\text { Çevre İzin ve Lisans Belgesinin alınmış } \\
\text { olması } \\
\text { - Alternatif hammadde olarak uçucu kül, arıtma } \\
\text { çamuru ve işlenmemiş cüruf atıklarının } \\
\text { kullanım lisansının alınmış olması } \\
\text { - Tehlikeli Madde Faaliyet Belgesi ve Tehlikeli } \\
\text { Madde Uygunluk Belgesinin alınmış olması } \\
\text { - Sera Gazı ve Çevre Danışmanları ile çalışıyor } \\
\text { olmak. } \\
\text { - Petrokok kullanım izninin oluşu }\end{array}$ \\
\hline ZAYIF YÖNLER & $\begin{array}{c}\text { TEHDİTLER } \\
\end{array}$ \\
\hline $\begin{array}{l}\text { - Çevre konusunda çalışanların yeterince } \\
\text { bilinçli olmaması } \\
\text { - Çevre kirliliğine yeterli önem verilmemesi } \\
\text { - Saha içerisinde tehlikesiz atıkların belirli } \\
\text { noktalar dışında da muhafaza edilmesi } \\
\text { - Tehlikeli atık alanında atıkların düzenli olarak } \\
\text { istiflenmemesi }\end{array}$ & $\begin{array}{l}\text { - } \mathrm{NOx}, \mathrm{SO}_{2} \text { ve toz değerlerinin artması ile hava } \\
\text { kirliliğinin artış göstermesi } \\
\text { - Sera gazı emisyonu olan } \mathrm{CO}_{2} \text { yıl içerisinde } \\
\text { artması hava kirliliğinin artış göstermesi }\end{array}$ \\
\hline
\end{tabular}

\subsubsection{Alternatif Hammaddelerin Tesise Kabulü, Hazırlanılması ve Kullanılması}

Alternatif hammadde olarak kullanılacak atıkların tesise kabulü "alternatif hammaddelerin kabulü ve kullanımı talimatı" kapsamında gerçekleştirilmiştir. Tesise kabul edilen alternatif hammaddeler Uçucu Kül, Arıtma Çamuru ve Cüruf işleme atıklarıdır. Uçucu kül klinker kullanım oranını azaltırken arıtma çamuru ve cüruf işleme atıkları da farin üretiminde kalite parametrelerinin ayarlanmasında katk1 sağlamaktadır. $\mathrm{Bu}$ sayede atık geri kazanımı ve değerlendirilmesi ile birlikte baca gazı karbon emisyonlarında yüksek oranda düşüş yaşanacağ öngörülmektedir.

\subsubsection{Alternatif Yakıt Kullanımı}

Orhan [25] tarafından yapılan çalışmada, Çimento sektörü enerjiyi yoğun kullanan bir sektör olarak tanımlanmış ve sera gazı emisyonlarının azaltılması ve doğal kaynak tüketiminin sınırlı tutulabilmesi açısından alternatif yakıt kullanımının büyük önem taşıdığı bildirilmiştir. Çalışmaya konu olan tesiste atık yakma lisansı henüz alınmamıştır. Ancak, konu ÇYS SWOT analizinde incelenmiştir. Üretimde alternatif yakıt kullanımı hedefler arasına alınarak konuyla ilgili çalışmalar devam etmektedir.

\subsection{Kimyasal Malzeme Yönetimi}

ÇYS kapsamında kimyasal malzeme yönetimi için "Kimyasalların Depolanma ve Kullanım Talimatı" oluşturulmuştur. Bu doküman sayesinde kimyasal 
malzemelerle çalışan personel kimyasalların etkileri, kullanma biçimleri, acil durumlarda yapılacak işlemler hakkında eğitilmiştir. Bu sayede hem kendi sağlık ve güvenlikleri hem de fabrikaya ve çevreye gelecek olası zararlar engellenerek azaltılmıştır.

\subsubsection{Atık Isı Kazanımı}

Fabrikada enerji tasarrufu ve verimli kullanılması amacıyla WHR projesi başlatılmıştır. Proje ile ısıl değeri yüksek atık gazların enerjisi buhar kazanlarında buhara dönüştürülmektedir. Oluşan buhar, sonrasında, türbine gönderilmekte ve "Jeneratör" yardımıyla elektrik enerjisi üretilmektedir. WHR tesisinin kurulu gücü 9,9 MWh olarak hesaplanmıştır.

Sönmez Çimento Farikası için atık ısıdan üretilecek enerji miktarı aşağıda hesaplanmıştır;

Y1llık klinker üretimi

1.815 .000 ton/y1l

Yıllık çalışma süresi

$330 * 24=7.920$ saat

Y1llı elektrik üretimi 1.815.000*43,2=78,408 MW

Saatlik elektrik üretimi

$78.408 / 7920 \cong 9,9 \mathrm{MWh}$

Termal Isıl Güç

$9,9 / 0,21 \cong 47,14 \mathrm{MWt}$

Bu durumda projeye konu WHR tesisinin 1sıl gücü maksimum 47,14 MWt olarak saptanmıştır.

Benzer şekilde Khurana ve arkadaşları [11] atık 1s1 geri kazanım sistemiyle, yaklaşık olarak 4,4 MW elektrik enerjisi üretilebileceğini ortaya koymuşlardır.

WHR projesi ile, sektörel enerji yoğunluğunun düşmesine katkıda bulunulması, enerji maliyetlerinin azaltılması ve karlılığın artırılması, enerji fiyatlarında artış riskinin azaltılması, elektrik arz güvenilirliğinin artırılması, çevre imajının güçlendirilmesi ve $\mathrm{CO}_{2}$ emisyonları azaltılarak ticareti için fırsat yaratılması gibi kazanımların elde edilmesi öngörülmektedir. Bunun yanında, WHR fabrika üretim hattında gereksinim duyulan elektrik enerjisinin bir bölümünü de karş1layacak ve enerji giderini azaltacaktır. Ayrıca, ISO 14001 ÇYS ile amaçlanmış olan çevre dostu yaklaşım, baca/sera gazı emisyonlarının azalmasına yol açacaktır. Böylece SWOT analizinde belirtilen riskler fırsata çevrilmiş olacaktır. Nitekim, Wang ve arkadaşları [25] yaptıkları çalışmada, çimento sektöründe enerji kullanımının yoğun olması nedeniyle, ön isitıcıdan bacaya giden atık ısının geri kazanılarak değerlendirilmesi gerektiğini ifade etmiştir.

\section{5. İklim Değişikliğine Etkisi}

ÇYS'nin tesiste uygulanmasiyla iklim değişikliğinde etken olan sera gazı emisyonlarını azaltmak da bir hedef olarak belirlenmiştir. Bu amaçla sera gazı emisyonlarını kontrol altına alabilmek için prosedürler ve talimatlar oluşturulmuştur. Tesiste klinker üretimi ve yakitların yanmasindan kaynaklanan $\mathrm{CO}_{2}$ emisyonlarının hesaplanmasinda HTY'den yararlanılmıştır. HTY, yakıtların yanmasını ve prosesten kaynaklanan sera gazı emisyonlarını göz önünde bulundurularak uygulanan bir yöntemdir. $\mathrm{Bu}$ yöntemde emisyonlar, ölçüm sistemleri aracılığıyla kaynak akışlarından elde edilen faaliyet verisinin laboratuvarda analiz edilmesiyle ya da emisyonların varsayılan ilave parametrelerinden yararlanılarak hesaplanmaktadır. Yakıtların yanması esnasında tüketilen yakıta ait veriden yararlanılırken, prosesten kaynaklı emisyonlarda, giren ve çıkan malzemeye ilişkin veriye ya da Kütle Denge Yöntemi'ne başvurulmaktadır. Bu şekilde Faaliyet Verisi belirlenmektedir.

Bu çalışmada HTY ile emisyonların hesaplanması için standart yöntem uygulanmıştır. Proses emisyonlarının hesaplanmasında Tebliğin Ek 3'ünde verilen tesisler ile ilgili faaliyete özgü izleme yöntemi kullanılmıştır. Tesiste sera gazı emisyonlarının ÇYS'ye entegre edilmesi ile Sera Gazı Emisyonlarını İzleme ve Raporlama Prosedürü oluşturulmuştur. Prosedürde tanımlanmış olan, 2019 yılına ait faaliyetler Çizelge 4'de, tesisin 2019 yılına ait emisyon kaynakları ise Çizelge 5'de gösterilmiştir. 
Çizelge 4. 2019 yılı sera gazı emisyonları tanımlanmış faaliyetler

\begin{tabular}{|c|c|c|c|c|}
\hline Etiket & Faaliyet & Toplam Faaliyet Kapasitesi & Birim & Sera Gazları \\
\hline F1 & Klinker Üretimi & 5,500 & ton/gün & $\mathrm{CO}_{2}$ \\
\hline F2 & $\begin{array}{c}\text { Yakitların } \\
\text { Yanmas1 }\end{array}$ & 320,44 & $\begin{array}{c}\text { MWth } \\
\text { (saatte ton MW) }\end{array}$ & $\mathrm{CO}_{2}$ \\
\hline
\end{tabular}

Çizelge 5. 2019 yılı sera gazı emisyonları emisyon kaynakları

\begin{tabular}{|c|c|c|}
\hline Etiket & Kaynak & Ilişkili Faaliyetler \\
\hline K1 & Döner Fırın & Klinker Üretimi \\
\hline K2 & Kalsinatör & Klinker Üretimi \\
\hline K3 & Jeneratör 1 & Yakıtların Yanması \\
\hline K4 & Jeneratör 2 & Yakıtların Yanmas1 \\
\hline K5 & Jeneratör 3 & Yakıtların Yanmas1 \\
\hline K6 & Jeneratör 4 & Yakıtların Yanmas1 \\
\hline K7 & Yangın Pompas1 & Yakıtların Yanması \\
\hline K8 & HGG 1 & Yakıtların Yanmas1 \\
\hline K9 & HGG 2 & Yakıtların Yanmas1 \\
\hline K10 & Şalomalar & Yakıtların Yanmas1 \\
\hline
\end{tabular}

Orhan [25] yaptığı çalışmada, çimento üretiminden kaynaklanan sera gazı emisyonlarının çimento üretiminde $\mathrm{CO}_{2}$ klinkerleşme sürecinde meydana geldiğini ve karbonat içerikli hammaddelerin yüksek 1sı ile reaksiyona girmesi sonucu $\mathrm{CO}_{2}$ açığa çıktığını bildirmiştir. Çimento sektörünün enerjiyi yoğun kullanan sektörlerin başında gelmesinden dolayı sera gazı emisyonlarının azaltılması ve doğal kaynak tüketiminin sınırlı tutulabilmesi açısından alternatif yakıt kullanımının büyük önem taşıdığını belirtmiştir. $\mathrm{Bu}$ çalışmada da yakıt tüketimlerinin azaltılması ve alternatif hammadde kullanımlarının artması için ISO 14001 ÇYS kapsamında hedefler konulmuş olup böylece enerji kazanımını artırma yönünde olumlu dönüşler alınmıştır. Çizelge 6 ve Çizelge 7'de sırasıyla 2017 ve 2019 yıllarına ait kullanılan yakıtlar ve bu yakıtların yanması sonucu salınan $\mathrm{CO}_{2}$ emisyonları hesaplanmıştır. Hesaplamada Başlık 3.2. Metotta tanımlanan yöntem kullanılmıştır. 2017 yılında çalışma konusu fabrikada ÇYS uygulamaları henüz hayata geçirilmemiştir ve 2019'a kadar geçen iki yıl süresince ÇYS yürürlüğe alınmış ve özellikle yakıt tüketimlerinin azaltılması ve alternatif hammadde kullanımlarının artması için ISO 14001 ÇYS kapsamında hedefler yakalanmaya çalışılmıştır. Buna göre, 2017 ve 2019 yılları arasında $\mathrm{CO}_{2}$ emisyonu azalması 6811,87 ton olarak gerçekleşmiştir.

Çizelge 6. 2017 yılı örnek hesaplama

\begin{tabular}{|l|r|r|r|r|}
\hline & Faaliyet Verisi $(\mathrm{t})$ & $\mathrm{NKD}(\mathrm{GJ} / \mathrm{t})$ & $\mathrm{EF} \mathrm{tCO}_{2} / \mathrm{TJ}$ & \multicolumn{1}{c|}{$\mathrm{tCO}_{2} \mathrm{e}$} \\
\hline Klinker & $1.758 .396,95$ & & 0,53 & $931.950,39$ \\
\hline KOK & $1.758 .396,95$ & & 0,011358 & $19.971,87$ \\
\hline Petrokok & $124.197,31$ & 32,24 & 97,28 & $389.520,92$ \\
\hline İthal Linyit & $53.827,86$ & 26,85 & 95,84 & $138.515,45$ \\
\hline Motorin & 85,59 & 43,33 & 73,38 & 272,14 \\
\hline Propan & 3,15 & 47,3 & 63,1 & 9,40 \\
\hline TOPLAM & & & & $\mathbf{1 . 4 8 0 . 2 4 0 , 1 7}$ \\
\hline
\end{tabular}


Çimento Üretim Sektöründe ISO 14001 Çevre Yönetim Sisteminin Enerji Kazanımı ve İklim Değişikliği Üzerine Etkilerinin Incelenmesi

Çizelge 7. 2019 yılı örnek hesaplama

\begin{tabular}{|l|r|r|r|r|}
\hline & Faaliyet Verisi $(\mathrm{t})$ & $\mathrm{NKD}(\mathrm{GJ} / \mathrm{t})$ & $\mathrm{EF} \mathrm{tCO} / \mathrm{TJ}$ & \multicolumn{1}{|c|}{$\mathrm{tCO}_{2} \mathrm{e}$} \\
\hline Klinker & $1.746 .544,22$ & & 0,53 & $929.161,53$ \\
\hline KOK & $2.707 .143,54$ & & 0,011358 & $11.813,97$ \\
\hline Petrokok & $144.255,78$ & 31,95 & 91,54 & $421.905,31$ \\
\hline İthal Linyit & $47.712,15$ & 23,78 & 97.10 & $110.169,17$ \\
\hline Motorin & 172,10 & 43,00 & 74,10 & 548,36 \\
\hline LPG & 0,63 & 47,30 & 63,10 & 1,88 \\
\hline Kömür & 0,12 & 28,20 & 94,60 & 0,32 \\
\hline Propan & 9,27 & & 2,99 & 27,75 \\
\hline TOPLAM & & & & $\mathbf{1 . 4 7 3 . 6 2 8 , 2 9}$ \\
\hline
\end{tabular}

\section{SONUÇLAR VE ÖNERİLER}

İklim değişikliği günden güne önem kazanan bir konudur. $\mathrm{Bu}$ nedenle insan faaliyetlerinin sebep olduğu sera etkisine sebep olan gazlara yönelik önlem alınması son derece önem arz etmektedir. Bunun yanında enerjinin etkin kullanımı ve tasarrufuna yönelik çalışmalar da günümüzde oldukça üzerinde durulan konulardır.

Bu kapsamda Sönmez Çimento fabrikasında yürütülen bu çalışmada, oluşturulan ÇYS ile emisyonların izlenmesi ve raporlanması hususunda takip edilebilir ve sürdürülebilir bir başarı elde edilmiştir. Fabrikanın $\mathrm{CO}_{2}$ salınımı iki yılda 6811,87 ton oranında azaltılmıştır. Bunun yanında atık ısının geri kazanılması için kurulan WHR tesisi sayesinde 47,14 MWt oranında bir enerji kazanımı elde edilmiştir. $\mathrm{CO}_{2}$ azalması ve enerji kazanımı paralelinde alternatif hammadde kullanımı ise \%30 oranında artmıştır.

$\mathrm{Bu}$ sayede fabrikanın toplum, müşteriler ve yatırımcılar üzerinde sağlam bir güven duygusu yaratacağı öngörülmektedir. Bunun paralelinde çevreye duyarlı bir firma imajının da artacağ düşünülmektedir. Çimento üretiminde enerjinin etkin kullanılması, tüketiminin azaltılması ve iklim değişikliğine olan etkisinin düşürülmesi için sürekli iyileştirme faaliyetlerinin takip edilebilir ve sürdürülebilir bir şekilde yürütülmesi gerekmektedir.

\section{KAYNAKLAR}

1. TÇMB, 2019. https://www.tcma.org.tr/ Erişim Tarihi: 08.10.2019 saat: 17:05

2. Erdoğan, A., 2008. İklim Değişikliği ile Mücadele Faaliyetlerinin Türk Çimento Sanayiine Etkileri, Uzmanlık Tezi, 174.

3. Cembureau, Activity Report, https://cembureau.eu/media/1635/activityreport-2016.pdf, 2016

4. Söğüt, Z., Oktay, Z., Karakoç, H., Yörü, Y., 2010. Kuru Tip Çimento Üretiminde Farin Değirmenin Termoekonomik Analizi. Is1 Bilimi ve Tekniği Dergisi, Eskişehir, 30(1), 59-72.

5. Syed, R.H., Istiak, A., Ferdous, S.A., Monjorul, H., 2020. Empirical Investigation of Energy Management Practices in Cement Industries of Bangladesh. Energy, 212, 1-13. 118741.

6. Zhang, S., Xie, Y., Sander, R., Yue, H., Shu, Y., 2021. Potentials of Energy Efficiency Improvement and Energy Emission Health Nexus in Jing-Jin-Ji's Cement Industry, Journal of Cleaner Production, 278, 1-15, 123335

7. Özdenkoş, O., 2010. Çimento Fabrikalarında Kalite ve Çevre Yönetimi Sistemleri: Sektörde Bir Uygulama. Yüksek Lisans Tezi, İzmir, 178.

8. Kuleli, Ö., 2010. Çimento Mühendisliği El Kitab1, Ankara, 11.1

9. Doğanay, M., 2000. Tekstil Endüstrisinde Çevre Yönetim Sistemi Uygulaması. Yüksek Lisans Tezi, İstanbul, 160. 
10. Ofori, G., Gang, G., Briffett, G., 2002. Implementing Environmental Management Systems in Construction: Lessons from Quality Systems. Building and Environment 37, 1397- 1407.

11. Khurana, S., Banerjee, R., Gaitonde, U., 2002. Energy Balance and Cogeneration for a Cement Plant, Applied Thermal Engineering. 22(5), 485-494.

12. Melnyk, S., 2003. A Model of Site- Specific Antecedents of ISO 14001 Certification, Production and Operations Management, 12(3), 369- 385 .

13. Fryxell, G., Lo, C., Chung, S., 2004. Influence of Motivations for Seeking ISO 14001 Certification on Perceptions of EMS Effectiveness in China. Environmental Management 33(2), 239- 251.

14. Bektaş, H., 2005. Madencilikte Çevre Yönetim Sistemi Uygulaması: TS EN ISO 14001. Ankara, Madencilik ve Çevre Sempozyumu

15. Worrell, E., Bernstein, L., Roy, J., Price, L., Harnisch, J., 2008. Industrial Energy Efficiency and Climate Change Mitigation. Energy Efficiency, 2, 109-123.

16. Wang, J., Dai, Y., Gao, L., 2009. Exergy Analyses and Parametric Optimizations for Different Cogeneration Power Plants in Cement Industry. Applied Energy, 86(6), 941-948.

17. Hasanbeigi, A., Price, L., Lu, H., Lan, W., 2010. Analysis of Energy-efficiency Opportunities for the Cement Industry in Shandong Province, China: A Case Study of 16 Cement Plants, Energy. 35(8), 3461-3473.

18. Aydın, M.E., Bedük, F., 2010. İşletmelerde Çevre Yönetimi ve Karaman İli için Bir Örnek Uygulama. SÜ İ̈BF Sosyal ve Ekonomik Araştırmalar Dergisi, 10(19), 403-414.

19. Madlool, N.A., Saidur, R., Rahim, N.A., Islam, M.R., Hossian, M.S., 2012. An Exergy Analysis for Cement Industries: An Overview, Renewable \& Sustainable Energy Reviews. 16(1), 921-932.

20. Ertuğrul, İ., Şavlı, A., 2013. ISO 14001 Çevre Yönetim Sistemi ve Bakır Mamulleri Sanayine Uyarlanması. Çankırı Karatekin Üniversitesi İktisadi ve İdari Bilimler Fakültesi Dergisi, Cilt 3, Say1 2, 223-238
21. Hasanbeigi, A., Price, L., Lin, E., 2012. Emerging Energy-efficiency and $\mathrm{CO}_{2}$ Emission-reduction Technologies for Cement and Concrete Production: A Technical Review. Renewable and Sustainable Energy Reviews 16(8), 6220-6238.

22. Mikulčić, H., Klemeš, J.J., Vujanović, M., Urbaniec, K., Duić, N., 2016. Reducing Greenhouse Gasses Emissions by Fostering the Deployment of Alternative Raw Materials and Energy Sources in the Cleaner Cement Manufacturing Process. Journal of Cleaner Production, 136, 119-132.

23. Van Ruijven, Bas, J., Detlef, P., Vuuren, V., Boskaljon, W., Maarten L., Neelis, Saygin, D., Martin, K., Patel., 2016. Long-term Modelbased Projections of Energy Use and $\mathrm{CO}_{2}$ Emissions from the Global Steel and Cement Industries. Resources, Conservation and Recycling, 112, 15-36.

24. Topçu, F.H., 2018. Düşük Karbon Ekonomisine Geçme(me): İklim Değişikliği ve Enerji Politikaları Bağlamında Bir Bakış. Akdeniz İ.İ.B.F. Dergisi, 115-154.

25. Orhan, A.E., 2018. Çimento Üretiminden Kaynaklanan Sera Gazı Emisyonlarının Hesaplanması, Yüksek Lisans Tezi, Ankara, 156.

26. Wang, J., Dai, Y., Gao, L., 2009. Exergy Analyses and Parametric Optimizations for Different Cogeneration Power Plants in Cement Industry. Applied Energy, 86(6), 941-948.

27. Terrados, J., Almonacid, G., Hontoria, L., 2007. Regional Energy Planning Through SWOT Analysis and Strategic Planning Tools: Impact on Renewables Development. Renewable and Sustainable Energy Reviews 11(6), 1275-1287. 
